\title{
Epidemiological profile and strategies for diagnosing SIDS in a developing country
}

\author{
Ana Paula Silveira Pinho, ${ }^{1}$ Magda Lahorgue Nunes ${ }^{2}$
}

\begin{abstract}
Objective: To describe the epidemiological profile, risk factors and best strategies for diagnosing sudden infant death syndrome (SIDS) in a developing country.

Methods: Population-based, case-control study with children born between January 1st, 2001, and December 31st, 2003, in Porto Alegre, southern Brazil, who were allocated into three groups: SIDS cases (33), explained death controls (192), and living controls (192). Children in the latter two groups were age- and sex-paired with SIDS cases. Families in which an infant had died at home within the first year of life were identified, and the information available on death certificates and autopsy reports was compared to confirm the diagnosis of SIDS. Explained death controls consisted of infants who had died at city hospitals, and living controls were selected in the same neighborhood as SIDS cases. All parents were interviewed to obtain information on children's health and sleep habits. Multivariate analysis was performed to identify risk factors in the study population.

Results: The incidence of SIDS in the population assessed was $0.55 / 1,000$ live births. The analysis revealed the following risk factors: ethnicity (characterized by self-reported black skin color), prematurity, low birth weight, adolescent mother, smoking during pregnancy, and family income of less than one minimum wage. Ninety-four percent of SIDS cases were misdiagnosed in the death certificate.

Conclusions: Although SIDS was misdiagnosed in official death certificates, the epidemiological profile is similar to the literature, as well as risk factors, which could be reduced with preventive campaigns. Investigating SIDS in developing countries requires special strategies to avoid misdiagnosis.
\end{abstract}

J Pediatr (Rio J). 2011;87(2):115-122: SIDS, epidemiology, prone sleeping position.

\section{Introduction}

Sudden infant death syndrome (SIDS) is defined as the sudden death of any infant under 1 year of age which remains unexplained after a thorough case investigation, including complete post-mortem examination, review of clinical history, and examination of death scene. ${ }^{1}$ There is no agreement with respect to SIDS physiopathology. However, many hypotheses have been raised in the last years. ${ }^{2,3} \mathrm{~A}$ great deal of the advances in SIDS knowledge is related to the discovery of environmental risk factors, the so-called "triggers," which may contribute to the occurrence

1. MD. PhD. Pediatric neurologist, Division of Neurology, Hospital São Lucas, Pontifícia Universidade Católica do Rio Grande do Sul (PUCRS), Porto Alegre, RS, Brazil.

2. MD. PhD. Associate professor, Neurology, School of Medicine, PUCRS, Porto Alegre, RS, Brazil.

No conflicts of interest declared concerning the publication of this article.

Suggested citation: Pinho AP, Nunes ML. Epidemiological profile and strategies for diagnosing SIDS in a developing country. J Pediatr (Rio J). 2011;87(2):115-122.

Manuscript submitted Sep 13 2010, accepted for publication Nov 302010.

doi:10.2223/JPED.2068 
of death in an organically predisposed child. 4-8 Currently, there is a wide range of risk factors associated with SIDS, some of which definitely correlated to it and others whose implications need to be confirmed. Prone sleeping position and smoking mothers are definite risk factors for the syndrome in developed countries. ${ }^{1}$

Since the 1970s, much has been learned about the epidemiology of SIDS and associated risk factors, successfully contributing to reduce the incidence of the event, for example by supine sleeping position campaigns. ${ }^{9-12}$ Some studies have shown other important risk factors for SIDS, including smoking during pregnancy, adolescent pregnancy, overheated environment and death in colder weather. Moreover, other proposed risk factors, such as low socioeconomic status, African descent and prematurity, are still under investigation. ${ }^{13}$ Overall, the causes of SIDS continue to be elucidated, leading to a renewed interest in investigating these patients. ${ }^{13-15}$

SIDS is largely misdiagnosed in death certificates and autopsy reports in Brazil: in another study, we have demonstrated that, until 2000, not a single case of SIDS (International Classification of Diseases, 10th revision, ICD-10, code R95) appeared in official mortality records in southern Brazil, whereas a retrospective analysis revealed that the syndrome had been misdiagnosed in many cases. ${ }^{16,17}$ This fact underscores the importance of describing the specific risk factors and epidemiological aspects associated with SIDS ${ }^{16,17}$ as to allow the development of adequate prevention campaigns and to provide new insights into the syndrome. ${ }^{9-12}$

The objectives of the present study were: 1) to describe the epidemiological profile of SIDS in the city of Porto Alegre; and 2) to investigate to what extent the risk factors reported in the literature affect this population.

\section{Methods}

The present population-based, case-control study was carried out with infants born in the city of Porto Alegre, southern Brazil, between January 1st, 2001, and December 31st, 2003, according to databases of the Porto Alegre Municipal Health Bureau.

The population of interest consisted of all the children born live in the study period. Children selected for the study were divided into three groups: SIDS, other explained death causes, and living controls. For each child in the SIDS group, six controls who had died due to other explained causes and six living controls were selected (in some cases, only five living controls were obtained). Controls were paired with SIDS cases based on sex and age at death (months).

Cases (SIDS patients, ICD-10 R95) were infants between 28 and 364 days old who died during their regular period of sleep and in their usual sleeping location, without previous clinical history of diseases that might explain the death, and who were submitted to autopsy. Exclusion criteria were explained death, death outside the home, evident signs of acute disease in the days preceding the death, and chronic diseases.

The group of infants who died of explained causes was selected among children older than 28 days who had been admitted to one of the city hospitals at least 48 hours before death and deceased due to well-defined causes, during hospital admission, in the same months as SIDS cases. Children younger than 28 days, with congenital malformations, and who died of unnatural causes according to the death certificate were excluded.

Data concerning the SIDS group and the group of explained deaths were obtained from the Brazilian database Sistema de Informações sobre Mortalidade ${ }^{18}$ and from hospital records. Living controls were selected among children living on the same streets as SIDS cases, trying to avoid any social selection bias.

A questionnaire including the main risk factors for SIDS described in the literature was applied to the parents or legal guardians of the children who had died (SIDS and explained deaths), during home visits. The interviews were conducted within 10 days after the child's death by trained volunteers from the city health department. Interviewers were blinded to group allocation (SIDS or explained death), and none of the families refused to participate in the study. Interviews with parents/guardians of the living children were conducted immediately after interviews with parents/guardians of SIDS cases by one of the researchers (APSP); these parents/guardians also answered the SIDS risk factor questionnaire. ${ }^{16,17}$ Whenever an invited family refused to participate in the study, another child living in the same street or neighborhood was selected and then the family was interviewed.

The strategy employed to recognize suspected SIDS cases was based on a questionnaire developed by the mortality surveillance program of the Porto Alegre Municipal Health Bureau available at the time, named Prá-Viver. The instrument has been previously used by us in another study. ${ }^{16}$ In the program, all families of children living in Porto Alegre who died in the first year of life are visited and interviewed by an expert professional to investigate disease and death history. Parents generally agree to be included in the program, and the refusal rate is around $2.5 \%$. The questionnaire consists of questions regarding well-established SIDS risk factors and general risk factors for infant mortality in our region.

SIDS diagnosis was based on an extensive review of the patient's clinical history, on the report provided by the family concerning the conditions of death, and on a negative post-mortem examination, according to the definition of the National Institute of Child Health and Human Development. ${ }^{1}$ 
Autopsy reports were provided by the Porto Alegre Forensic Medical Institute. The autopsies were conducted by a coroner and followed a protocol that included macroscopic examination of all organs. Autopsy reports were reviewed in detail by one of the authors (MLN) and compared with the information available on the death certificates.

The study variables included infant sex and age, gestational age at birth, ethnicity (defined by self-declared skin color), birth weight, Apgar score, history of hospital admissions, exclusive breastfeeding, access to specialized child care, history of previous chronic or acute disease, usual sleeping position, sibling with SIDS, immunization record, maternal age at birth, interval between deliveries, prenatal examinations, type of delivery, and smoking during pregnancy. Preterm infants were included, like in all previous population studies of SIDS, as this group per se has an increased risk of sudden death. ${ }^{19}$ The following socioeconomic and environmental variables were also investigated: season of death, family income, maternal marital status and schooling, and paternal schooling.

\section{Sample size calculation}

Considering the design of the study and using the formula $\mathrm{n}=02$ p.q. $\mathrm{N} / \mathrm{e} 2(\mathrm{~N}-1)+02 . p . q$, the sample estimate was one case for three controls. However, because of the elevated number of variables analyzed, it was decided to increase the number of controls.

\section{Statistical analysis}

Frequency tables were obtained for all the variables under study. The distribution of each variable was examined. For quantitative variables, the following central tendency and dispersion measures were used: arithmetic means, mode and standard deviation. Categorical variables were presented as percentages.

Univariate analysis was performed to detect differences between cases and the two control groups. The measure of association employed was the paired odds ratio with a $95 \%$ confidence interval. A multivariate analysis was subsequently carried out to identify the best model to explain the risk factors in the population under study. For that, a conditional logistic model was used, including the variables presenting statistical association with SIDS in the univariate analysis ( $p \leq 0.05$ ), as well as the most important variables reported in the literature. All the tests were carried out using the Statistical Package for the Social Sciences (SPSS) software, version 9.0.

The study protocol was approved by the Ethics Committee and Scientific Committee at Pontifícia Universidade Católica do Rio Grande do Sul, by the Porto Alegre Municipal Health Bureau, and by the board of directors of Porto Alegre Forensic Medical Institute.

\section{Results}

Between January 2001 and December 2003, 60,093 children were born alive in the city of Porto Alegre, and among them 365 died before 1 year of age.

After comparing information available on death certificates and autopsy reports, 33 of the 365 deaths $(9.0 \%)$ were categorized as SIDS, although only two of them received the diagnosis of SIDS on the death certificate. The incidence of the syndrome in the population assessed was $0.55 / 1,000$ live births.

A total of 417 children were included in the study: 33 SIDS cases, 192 infants who died of well-defined causes, and 192 living controls. Deaths in the group of explained deaths ( $n=192$ children), as recorded on death certificates using ICD-10, were due to carbonization (T29) ( $0.4 \%$ of cases); cranioencephalic trauma (S60), tuberculosis (A19), and lung emphysema (J43) (0.9\% each one); inborn errors of metabolism (E70, E90) $(1.2 \%)$; acute renal failure (N17) and meningitis (G03) ( $2.1 \%$ each one); acute gastroenteritis (A09) (10.6\%); and septicemia (A40) (43.1\%).

\section{Infant variables}

In the SIDS group, $57.5 \%$ were males (male:female ratio of $1.3: 1$ ). The mean gestational age at delivery was $8.3 \pm 1$ months (from 6 to 9 months) in SIDS cases, $8.3 \pm 1.0$ months in the group of explained deaths, and $8.8 \pm 0.4$ months among living children. Birth weight ranged from 1,000 to $3,700 \mathrm{~g}$ (mean: $2,600 \pm 0.9 \mathrm{~g}$ ) in the SIDS group, from 600 to $4,300 \mathrm{~g}$ (mean: $2,500 \pm 0.1 \mathrm{~g}$ ) in the group who died from explained causes, and from 1,100 to $4,800 \mathrm{~g}$ (mean: 3,310 $0.2 \mathrm{~g}$ ) in the living group.

The age of SIDS cases at death ranged from 1 to 10 months, with a mean of $3.0 \pm 2.0$ months; in the explained death group, the mean was $3.5 \pm 2.0$ months. Table 1 shows the frequency of previously determined SIDS risk factors in SIDS cases, explained death cases, and living controls. A predominance of lateral sleeping position was observed in all groups.

\section{Maternal and socioeconomic/environmental variables}

Maternal age at birth ranged from 14 to 39 years (mean: $22.3 \pm 6.0$ years) in the SIDS group, from 15 to 44 years (mean: $25.5 \pm 7.0$ years) in the group who died from other causes, and from 15 to 44 years (mean: $28.0 \pm 5.0$ years) in the group of living children. Twentyone mothers $(63.6 \%)$ in the SIDS group were adolescents (< 20 years), vs. $49(25.5 \%)$ in the group who died from explained causes, and $4(2.0 \%)$ in the living group. Table 2 shows the frequency of maternal and socioeconomic/ environmental risk factors among the groups. 
Table 1 - Frequency of infant-related risk factors for SIDS in the three study groups

\begin{tabular}{|c|c|c|c|}
\hline Variables & $\begin{array}{c}\text { SID } \\
\text { n (\%) }\end{array}$ & $\begin{array}{c}\text { Explained deaths } \\
\text { n (\%) }\end{array}$ & $\begin{array}{c}\text { Living controls } \\
\text { n (\%) }\end{array}$ \\
\hline \multicolumn{4}{|l|}{ Ethnicity* } \\
\hline Black & $10(30.3)$ & $55(28.6)$ & $27(14.0)$ \\
\hline White & $23(69.7)$ & $137(71.4)$ & $165(86.0)$ \\
\hline \multicolumn{4}{|c|}{ Premature birth $^{+}$} \\
\hline Yes & $6(18.2)$ & $51(26.5)$ & $20(10.5)$ \\
\hline No & $25(75.8)$ & $115(59.9)$ & $176(91.6)$ \\
\hline \multicolumn{4}{|c|}{ Birth weight $<2,500 \mathrm{~g}$} \\
\hline Yes & $8(24.2)$ & $77(40.1)$ & $16(8.4)$ \\
\hline No & $25(75.8)$ & $115(59.9)$ & $176(91.6)$ \\
\hline \multicolumn{4}{|c|}{ 5-minute Apgar score $<7$} \\
\hline Yes & $1(3.0)$ & $30(15.6)$ & - \\
\hline No & $32(97.0)$ & $162(84.4)$ & $192(100.0)$ \\
\hline \multicolumn{4}{|c|}{ Exclusive breastfeeding } \\
\hline Yes & $12(36.4)$ & $101(52.6)$ & $84(43.7)$ \\
\hline No & $21(63.6)$ & $91(47.4)$ & $108(56.3)$ \\
\hline \multicolumn{4}{|c|}{ Regular visits to a pediatrician } \\
\hline Yes & $18(54.5)$ & $154(80.2)$ & $155(80.7)$ \\
\hline No & $15(45.5)$ & $38(19.8)$ & $37(19.3)$ \\
\hline \multicolumn{4}{|c|}{ Acute disease } \\
\hline Yes & $2(6.0)^{\ddagger}$ & $189(98.5)$ & - \\
\hline No & $31(94.0)$ & $3(1.5)$ & $192(100.0)$ \\
\hline \multicolumn{4}{|c|}{ Sleeping position } \\
\hline Prone & $2(6.0)$ & $42(21.8)$ & $11(5.7)$ \\
\hline Lateral & $25(75.7)$ & $145(75.6)$ & $141(73.4)$ \\
\hline Supine & $6(18.3)$ & $5(2.6)$ & $40(20.9)$ \\
\hline \multicolumn{4}{|c|}{ SIDS sibling } \\
\hline Yes & $2(6.0)$ & - & - \\
\hline No & $31(94.0)$ & $192(100.0)$ & $192(100.0)$ \\
\hline \multicolumn{4}{|l|}{ Apnea } \\
\hline Yes & - & $21(11.0)$ & $3(1.6)$ \\
\hline No & $33(100.0)$ & $171(89.0)$ & $189(98.4)$ \\
\hline \multicolumn{4}{|c|}{ Immunization 48 hours before death } \\
\hline Yes & $4(12.1)$ & - & - \\
\hline No & $29(87.9)$ & $192(100.0)$ & - \\
\hline
\end{tabular}

SIDS = sudden infant death syndrome.

* Self-reported skin color.

$\dagger<37$ weeks' gestation. Information not available for all cases.

₹ Both cases considered to be without symptoms in the 48 hours prior to death.

Univariate analysis results are shown in Table 3. The multivariate analysis revealed the following risk factors for SIDS in this particular population: ethnicity (characterized by self-reported black skin color), prematurity, birth weight $<2,500 \mathrm{~g}$, adolescent mother, smoking during pregnancy, and family income of less than one minimum wage (Table 4).

\section{Discussion}

In the present study, we have analyzed risk factors for SIDS, comparing SIDS cases with infants deceased due to explained causes and with living controls. Although risk factors for the syndrome are highly prevalent in Brazil, the incidence of SIDS mortality has never been correctly estimated. In previous studies from our group, we have observed that SIDS cases were misdiagnosed and not correctly reported, ${ }^{16}$ and that the most usual recommended sleep position for infants is the lateral. ${ }^{17}$ Besides, we have also reported that SIDS cases in southern Brazil presented high-risk sleeping habits. ${ }^{20,21}$ The present study was designed based on the hypothesis that SIDS characteristics might not be unique to SIDS but to infant mortality in general and thus more related to poverty. In addition, the study assessed strategies used to recognize and diagnose 
Table 2 - Frequency of maternal and socioeconomic/environmental risk factors for SIDS in the three study groups

\begin{tabular}{|c|c|c|c|}
\hline Variables & $\begin{array}{c}\text { SID } \\
\text { n (\%) }\end{array}$ & $\begin{array}{c}\text { Explained deaths } \\
\text { n (\%) }\end{array}$ & $\begin{array}{c}\text { Living controls } \\
\text { n (\%) }\end{array}$ \\
\hline \multicolumn{4}{|l|}{ Maternal factors } \\
\hline \multicolumn{4}{|l|}{ Adolescent pregnancy* } \\
\hline Yes & $21(63.6)$ & $49(25.5)$ & $4(2.0)$ \\
\hline No & $12(36.4)$ & $143(74.5)$ & $188(98.0)$ \\
\hline \multicolumn{4}{|c|}{ At least one prenatal exam } \\
\hline Yes & $15(45.4)$ & $101(52.6)$ & $161(83.8)$ \\
\hline No & $18(54.6)$ & $91(47.4)$ & $31(16.2)$ \\
\hline \multicolumn{4}{|l|}{ Type of delivery } \\
\hline Vaginal & $26(77.7)$ & $160(83.3)$ & $128(66.6)$ \\
\hline C-section & $7(22.3)$ & $32(16.7)$ & $64(33.4)$ \\
\hline \multicolumn{4}{|l|}{ Smoking ${ }^{\dagger}$} \\
\hline Yes & $23(69.7)$ & $64(33.4)$ & $29(15.8)$ \\
\hline No & $10(30.3)$ & $128(66.6)$ & $163(84.2)$ \\
\hline \multicolumn{4}{|c|}{ Interval between deliveries } \\
\hline First child & $15(46.5)$ & $73(38.0)$ & $51(26.6)$ \\
\hline$>12$ months & $17(52.5)$ & $105(54.6)$ & $133(69.2)$ \\
\hline$\leq 12$ months & $1(1.0)$ & $14(7.4)$ & $8(4.2)$ \\
\hline \multicolumn{4}{|c|}{ Socioeconomic/environmental factors } \\
\hline \multicolumn{4}{|c|}{ Death in cold months } \\
\hline Yes & $12(36.4)$ & $124(64.5)$ & - \\
\hline No & $21(63.6)$ & $68(35.5)$ & - \\
\hline \multicolumn{4}{|l|}{ Family income } \\
\hline$\leq 1$ minimum wage & $10(33.4)$ & $40(20.8)$ & $8(4.1)$ \\
\hline$>1$ minimum wage & $23(66.6)$ & $152(79.2)$ & $184(95.9)$ \\
\hline \multicolumn{4}{|l|}{ Paternal schooling ${ }^{\ddagger}$} \\
\hline$\leq 4$ years & $1(1.0)$ & $18(10.9)$ & $9(5.7)$ \\
\hline$>4$ years & $32(99.0)$ & $151(89.1)$ & $159(94.3)$ \\
\hline \multicolumn{4}{|l|}{ Maternal schooling } \\
\hline$\leq 4$ years & $4(13.4)$ & $31(16.1)$ & $26(13.5)$ \\
\hline$>4$ years & $29(86.6)$ & $161(83.9)$ & $166(86.5)$ \\
\hline \multicolumn{4}{|l|}{ Single mother } \\
\hline Yes & $4(13.4)$ & $23(11.9)$ & $24(12.5)$ \\
\hline No & $29(86.6)$ & $169(88.1)$ & $168(87.5)$ \\
\hline
\end{tabular}

SIDS = sudden infant death syndrome.

* $<20$ years of age.

† Considered as yes when occurring anytime during pregnancy.

₹ Information not available for all cases.

the syndrome, as difficulties in identifying SIDS cases in developing countries are not only associated with a relatively high rate of infant mortality due to explained causes, most of them following infectious diseases, but also to difficulties in performing autopsies.

The selection of a group of children who died due to other explained causes and were not submitted to autopsy aimed at avoiding any confusion bias with SIDS. On the other hand, the selection of a group of living children had the objective of minimizing the number of possible selection biases, especially in terms of socioeconomic characteristics and in view of the great number of variables under analysis. The selection of these two control groups proved to be adequate and confirmed our hypothesis that SIDS is strongly associated with social and economic factors.

The incidence of SIDS in the study period was 0.55 per 1,000 live births, a result that is equivalent to rates currently found in the USA and in other countries that have advised against the prone sleeping position. ${ }^{22}$ This finding may reflect the effectiveness of prevention campaigns to reduce mortality and may also be influenced by the more favorable health indicators observed in the region where the study was developed (southern Brazil) as compared to the national average, and does not necessarily apply to other Brazilian states. Our results in terms of sex and age at death were also similar to those reported in the literature. ${ }^{22}$ 
Table 3 - Univariate analysis: infant-related, maternal, and socioeconomic/environmental risk factors for SIDS

\begin{tabular}{|c|c|c|}
\hline Variable & $\begin{array}{c}\text { SIDS } x \text { living children } \\
\text { OR }(95 \% C I)\end{array}$ & $\begin{array}{c}\text { SIDS } x \text { explained deaths } \\
\text { OR }(95 \% C I)\end{array}$ \\
\hline \multicolumn{3}{|l|}{ Infant-related risk factors } \\
\hline Black skin color & $3.6(1.5-7.3)$ & $1.5(0.2-9)$ \\
\hline Prematurity* & $1.9(0.7-5.1)$ & $0.6(0.2-1.5)$ \\
\hline Low birth weight & $3.5(1.3-9.1)$ & $0.4(0.2-1.1)$ \\
\hline 5-minute Apgar score $<7$ & $1.4(0.1-13)$ & $0.2(0.2-1.4)$ \\
\hline Hospitalization & $3.5(1.5-8.1)$ & $0.2(0.1-0.4)$ \\
\hline No exclusive breastfeeding & $0.7(0.3-1.5)$ & $0.5(0.2-1.1)$ \\
\hline No regular visits to a pediatrician & $0.3(0.1-0.6)$ & $0.3(0.1-0.6)$ \\
\hline Chronic disease & $0.7(0.3-1.5)$ & $0.05(0.01-0.1)$ \\
\hline Acute disease & - & $0.001(0.001-0.07)$ \\
\hline Prone position & $0.9(0.2-2.5)$ & $0.1(0.1-3)$ \\
\hline Apnea & - & - \\
\hline \multicolumn{3}{|l|}{ Maternal risk factors } \\
\hline Adolescent pregnancy ${ }^{\dagger}$ & $26.8(3.5-27.8)$ & $1.6(0.7-3.6)$ \\
\hline No prenatal exam & $0.1(0.1-0.3)$ & $0.7(0.3-1.5)$ \\
\hline C-section & $0.5(0.1-1.3)$ & $0.6(0.2-1.6)$ \\
\hline Smoking & $12.9(5.6-29)$ & $4.6(2.0-10.2)$ \\
\hline Short interval between deliveries & $0.9(0.4-1.9)$ & $0.4(0.1-1.2)$ \\
\hline \multicolumn{3}{|l|}{ Socioeconomic/environmental risk factors } \\
\hline Cold month ${ }^{\ddagger}$ & - & $0.9(0.4-2.0)$ \\
\hline Poverty & $10(5.0-26)$ & $1.6(0.7-3.8)$ \\
\hline Low level of paternal schooling & $1(0.5-3)$ & $0.5(0.1-3.5)$ \\
\hline Low level of maternal schooling & $0.8(0.4-3)$ & $0.7(0.3-2.5)$ \\
\hline Single mother & $0.6(0.2-2.1)$ & $0.9(0.4-4.2)$ \\
\hline
\end{tabular}

$95 \% \mathrm{Cl}=95 \%$ confidence interval; OR = odds ratio; SIDS = sudden infant death syndrome.

* $<37$ weeks' gestation.

$\dagger<20$ years of age.

‡ Deaths in cold months.

Table 4 - Multivariate analysis: risk factors for SIDS

\begin{tabular}{|c|c|c|}
\hline Variable & $\begin{array}{c}\text { SIDS } x \text { explained deaths } \\
\text { OR }(95 \% \mathrm{CI})\end{array}$ & $\begin{array}{c}\text { SIDS } x \text { living children } \\
\text { OR }(95 \% \mathrm{CI})\end{array}$ \\
\hline Black skin color & $1.5(1.1-9.0)$ & $3.0(1.2-4.5)$ \\
\hline Prematurity* & $0.5(0.2-1.5)$ & $1.3(1.1-5.0)$ \\
\hline Low birth weight & $0.1(0.08-1.1)$ & $3.0(1.3-7.0)$ \\
\hline Prone sleeping position & $0.08(0.01-1.0)$ & $0.5(0.2-0.9)$ \\
\hline Adolescent mother $^{\dagger}$ & $2.8(1.0-4.5)$ & $18.0(3.0-20.0)$ \\
\hline Smoking during pregnancy & $3.0(1.5-4.3)$ & $10.0(5.6-27.0)$ \\
\hline Family income $<1$ minimum wage & $1.1(1.0-3.0)$ & $8.0(2.3-20.0)$ \\
\hline
\end{tabular}

$95 \% \mathrm{Cl}=95 \%$ confidence interval; OR = odds ratio; SIDS = sudden infant death syndrome.

* $<37$ weeks' gestation.

$\dagger<20$ years of age. 
Sleeping position is undoubtedly the most widely studied risk factor in SIDS.7,8,23,24 In a recent European study, the most significant risk factors for the syndrome were sleeping in prone position and turning from the side to the prone position. ${ }^{25} \mathrm{~A}$ previous study carried out by our group found that $71 \%$ of SIDS cases usually slept in lateral position; of these patients, $52 \%$ were found dead in the same position and $19 \%$ were found in prone position. ${ }^{16}$ In the present study, very few infants used to sleep in prone position, probably because in Brazil the lateral sleeping position is advised for infants. ${ }^{26}$ In fact, the predominance of lateral sleeping position was similar in the three study groups, and therefore did not seem to have any impact on the outcome. The fact that "usual" sleeping position was recorded rather than the position in which the infant was sleeping in the last live night or the position in which he/ she was found dead is definitely a limitation of the present study. Nevertheless, our findings corroborate previous studies in the sense of asserting that recognizing sleeping habits potentially protective for SIDS and avoiding sleeping practices associated with an increased risk for SIDS may have a positive impact on reducing the incidence of SIDS in populations from regions where this information is not currently given to parents. 27,28

In the US, a higher frequency of SIDS has been reported in African Americans. ${ }^{29}$ In the present study, self-declared black skin color was significantly associated with SIDS. The limitation of this finding in our study refers to the fact that, in Brazil, races are defined based on the observed or selfreported skin color, which is not necessarily equivalent to ethnicity. Moreover, the black population in Brazil usually has worse socioeconomic conditions, a variable that was also significantly associated with SIDS in the present study and in previous publications. ${ }^{9}$

With regard to maternal variables, adolescent pregnancy is a known risk factor for several conditions, including SIDS. 27,28,30 This was also observed in our study: adolescent pregnancy presented the highest individual OR (18.0) in the comparison between SIDS and living controls. Environmental risk factors for SIDS such as perinatal exposure to smoking, parental smoking, ethanol intake, drug use, and socioeconomic disadvantage, are generally also more often reported in adolescent pregnancy. ${ }^{3}$ Furthermore, in a previous study that proposed a scoring system for SIDS risk factors, we have also observed that adolescent mothers were one of the most strongly associated highrisk factor for sleep practices, and it has been suggested that young mothers, as well as mothers with low education levels, place their infants to sleep in the prone position more frequently. ${ }^{20}$

Smoking was also strongly associated with SIDS in the present study. Postnatal exposure to cigarette smoke may trigger intrinsic responses in the vulnerable infant and have a direct effect on neurotransmitter systems that are critical to homeostatic control in the developing human brain. ${ }^{3}$ This is a reason for concern, since it has been shown that families that have a hard time quitting smoking also have a hard time changing other habits, such as the baby's sleeping position. ${ }^{31-33}$

It is interesting to observe that most of the risk factors for SIDS identified in the multivariate analysis in this particular population were preventable, namely prematurity, birth weight $<2,500 \mathrm{~g}$, adolescent pregnancy, and smoking during pregnancy. This finding reinforces the importance of developing and implementing public health campaigns aimed at high-risk populations with the purpose of controlling risk factors associated with SIDS and reducing mortality. ${ }^{1}$

Concerning environmental variables, family income was associated with SIDS even in comparison with the group of explained deaths. On the other hand, no statistical differences were observed in terms of deaths occurring during cold months (average 15 to $18{ }^{\circ} \mathrm{C}$ in the region) or with regard to maternal and paternal schooling, which differs from other reports. 27,30 A possible explanation regarding parental schooling might be related to the low cut-off point used in our sample, of less than 4 years of study, whereas the Brazilian primary educational system lasts 8 years. However, the high dropout rate observed in the country among the first 4 years of schooling justifies the cut-off point employed.

Some difficulties related to the study of SIDS in developing countries should also be mentioned. The main problem is that autopsy is not always available; whenever it is available, as is the case in Brazil (it was mandatory for all children dying at home during the study period), it is performed by a general coroner and does not include microscopic studies, which may explain the misdiagnosis of SIDS observed in our cases. All our SIDS cases were classified by the authors as category I SIDS, except for two that had SIDS siblings and could thus be classified as category II, following Beckwith's proposal. ${ }^{34}$ Nevertheless, according to Bergman, ${ }^{35}$ SIDS can be diagnosed, not with certainty, but with a high degree of probability, even in the absence of an autopsy. Therefore, the unavailability of autopsies should not prevent other investigators in developing countries from studying SIDS. On the other hand, we also believe that an effort should be made to establish autopsy as a routine procedure to investigate the death of children at home.

In conclusion, the present study showed that the epidemiological characteristics of SIDS patients in southern Brazil are compatible with other samples described in the literature. Moreover, the risk factors commonly associated with the syndrome in the literature were also observed not only in our SIDS group, but also in the explained death group. This confirms our hypothesis that most of SIDS risk factors are related to low socioeconomic conditions and poverty. Finally, it was possible to observe that the 
investigation of SIDS cases in developing countries requires special strategies to avoid misdiagnosis. Most of the risk factors associated with SIDS could probably be reduced via public health campaigns aimed at high-risk populations. Data presented in this study will also be important to compare in the future years the impact of the campaigns introduced last year, by Pastoral da Criança and Sociedade Brasileira de Pediatria, regarding sleep position, as no studies were already performed after the change of orientation from lateral to supine position, in Brazil.

\section{References}

1. Willinger $M$, James LS, Catz C. Defining the sudden infant death syndrome (SIDS): deliberations of an expert panel convened by the National Institute of Child Health and Human Development. Pediatr Pathol. 1991;11:677-84.

2. Sawaguchi A, Sawaguchi T, Matoba R, Togari H, Nakagawa S, Miyauchi J, et al. Study to increase the frequency of autopsies performed for cases of infant death - proposed revision of the law on the postmortem examination and corpse preservation and other related regulations. Forensic Sci Int. 2002;130 Suppl: S96-103.

3. Kinney HC, Thach BT. The sudden infant death syndrome. N Engl J Med. 2009;361:795-805

4. Hoffman HJ, Damus K, Hillman L, Krongrad E. Risk factors for SIDS. Results of the National Institute of Child Health and Human Development SIDS Cooperative Epidemiological Study. Ann N Y Acad Sci. 1988;533:13-29.

5. Malloy $\mathrm{MH}$. Trends in postneonatal aspiration deaths and reclassification of sudden infant death syndrome: impact of the "Back to Sleep" program. Pediatrics. 2002;109:661-5.

6. Willinger M, Hoffman $\mathrm{HJ}$, Wu K, Hou J, Kessler R, Ward S, et al. Factors associated with the transition to non prone sleep position of infants in the United States: the National Infant Sleep Position Study. JAMA. 1998;280:329-35.

7. Bolton DP, Taylor BJ, Campbell AJ, Galland BC, Cresswell C. Rebreathing expired gases from bedding: a cause of cot death? Arch Dis Child. 1993;69:187-90.

8. American Academy of Pediatrics AAP Task Force on Infant Positioning and SIDS: Positioning and SIDS. Pediatrics. 1992;89:1120-6.

9. Adams EJ, Chavez F, Steen D, Shah R, Iyasu S, Krous HF. Changes in the epidemiologic profile of sudden infant death syndrome as rates decline among California infants: 1990-1995. Pediatrics. $1998 ; 102: 1445-51$.

10. Dwyer T, Ponsonby AL. The decline of SIDS: a success story for epidemiology. Epidemiology. 1996;7:323-5.

11. Hiley $\mathrm{CM}$, Morley $\mathrm{CJ}$. Evaluation of government's campaign to reduce risk of cot death. BMJ. 1994;309:703-4.

12. Lewis J, Samuels $M$, Southall $D$. Is the decline in cot deaths due to child-health reogarnisation? Lancet. 1993;341:51.

13. Valdes-Dapena M. The sudden infant death syndrome: pathologic findings. In: Hunt $C E$, editor. Clinics in perinatology: apnea and SIDS. Philadelphia: WB Saunders; 1992. p. 701-16.

14. Spencer N, Logan S. Sudden unexpected death in infancy and socioeconomic status: a systematic review. J Epidemiol Community Health. 2004; 58:366-73.

15. Cote A, Russo P, Michaud J. Sudden unexpected deaths in infancy: what are the causes? J Pediatr. 1999;135:437-43.

16. Nunes ML, Pinho AP, Aerts D, Santacute;Anna A , Martins MP, Costa JC. Síndrome da morte súbita do lactente: aspectos clínicos de uma doença subdiagnosticada. J Pediatr (Rio J). 2001;77:29-34.
17. Pinho AP, Aerts $D$, Nunes ML. Risk factors for sudden infant death syndrome in a developing country. Rev Saude Publica. 2008;42:396-401.

18. CENEPI, DATASUS. Sistema de Informações sobre Mortalidade (SIM). http://www.datasus.gov.br/catalogo/sim.htm. Access: 2001-2003.

19. Blair PS, Sidebotham P, Berry PJ, Evans M, Fleming PJ. Major epidemiological changes in sudden infant death syndrome: a 20-year population-based study in the UK. Lancet. 2006;367:314-9.

20. Geib LT, Aerts D, Nunes ML. Sleep practices and sudden infant death syndrome: a new proposal for scoring risk factors. Sleep. 2006;29:1288-94.

21. Geib LT, Nunes ML. The incidence of sudden death syndrome in a cohort of infants. J Pediatr (Rio J). 2006;82:21-6.

22. Moon RY, Horne RS, Hauck FR. Sudden infant death syndrome. Lancet. 2007;370:1578-87.

23. Mitchell EA, Thompson JM, Ford RP, Taylor BJ. Sheepskin bedding and the sudden infant death syndrome. New Zealand Cot Death Study Group. J Pediatr. 1998;133:701-4.

24. Hunt CE, Shannon DC. Sudden infant death syndrome and sleeping position. Pediatrics. 1992;90:115-8.

25. Carpenter RG, Irgens LM, Blair PS, England PD, Fleming P, Huber $\mathrm{J}$, et al. Sudden unexplained infant death in 20 regions in Europe: case control study. Lancet. 2004;363:185-91.

26. Nunes ML, Martins MP, Nelson EA, Cowan S, Cafferata ML, Costa JC. Orientações adotadas nas maternidades dos hospitaisescola do Brasil, sobre posição de dormir. Cad Saude Publica. 2002; $18: 883-6$

27. Arntzen A, Moum T, Magnus $P$, Bakketeig LS. Is the higher postneonatal mortality in lower social status groups due to SIDS? Acta Paediatr. 1995;84:188-92.

28. L'Hoir MP, Engelberts AC, van Well GT, Bajanowski T, Helweg-Larsen $\mathrm{K}$, Huber J. Sudden unexpected death in infancy: epidemiologically determined risk factors related to pathological classification. Acta Paediatr. 1998;87:1279-87.

29. Unger B, Kemp JS, Wilkins D, Psara R, Ledbetter T, Graham M, et al. Racial disparity and modifiable risk factors among infants dying suddenly and unexpectedly. Pediatrics. 2003;111:E127-31.

30. Daltveit AK, Irgens LM, Oyen N, Skjaerven R, Markestad T, Alm $B$, et al. Sociodemographic risk factors for sudden infant death syndrome: associations with other risk factors. The Nordic Epidemiological SIDS Study. Acta Paediatr. 1998;87:284-90.

31. Nelson EA, Serra A, Cowan S, Mangiaterra V. Maternity advice survey: sleeping position in Eastern Europe. MAS Study Group for WHO EURO Region. Arch Dis Child. 2000;83:304-6.

32. Malloy MH. SIDS - a syndrome in search of a cause. N Eng J Med. 2004;351:957-9.

33. Blair PS, Fleming PJ, Bensley D, Smith I, Bacon C, Taylor E, et al. Smoking and the sudden infant death syndrome: results from 1993-5 case-control study for confidential inquiry into stillbirths and deaths in infancy. Confidential Enquiry into Stillbirths and Deaths Regional Coordinators and Researchers. BMJ. 1996;313:195-8.

34. Beckwith JB. Defining the sudden infant death syndrome. Arch Pediatr Adolesc Med. 2003;157:286-90.

35. Bergman $A B$. Studying sudden infant death syndrome in a developing country. J Pediatr (Rio J). 2006;82:4-5.

Correspondence:

Magda Lahorgue Nunes

Av. Ipiranga 6690, sala 220

CEP 90610-000 - Porto Alegre, RS - Brazil

Tel.: +55 (51) 3320.3318

Fax: +55 (51) 3320.3316

E-mail: nunes@pucrs.br 